the risk of ventricular arrhythmia among those with impaired LV function and $\mathrm{I}^{123} \mathrm{BMIPP}$, a fatty acid analog, to image the ischemic signature left behind in the myocardium from a recent ischemic insult. Adding new patient populations to our traditional diagnostic and prognostic role in the ischemic assessment is particularly exciting for growth and innovation in the field.
Nuclear cardiology and its complementary imaging brethren are destined to play an increasingly larger role as we strive to continually offer more advanced and effective care to those with cardiac disease and those at risk for its development.

Gregory S. Thomas, MD, MPH President

\title{
CALENDAR
}

\section{Meetings and Programs}

Please note that the programs listed below are sponsored or cosponsored by the American Society of Nuclear Cardiology (ASNC). For more information, visit the ASNC Web site (http://www.asnc.org/education/calendar.cfm)
December 6 - 8, 2007. Hands-On Training: Cardiac CT and CT Angiography. Chicago, Ill.

December 9 - 11, 2007. Hands-On Training: Cardiac CT and CT Angiography. Chicago, Ill.

December 14 - 15, 2007. CTA: Focus on Peripheral Vascular. Hands-On Case Interpretation. Chicago, Ill.

March 29, 2008. Nuclear Cardiology: Overview and Update. Chicago, Ill.

\section{CORRECTION}

In the Young Investigator Competition section of the Abstracts of Original Contributions ASNC2007 $12^{\text {th }}$ Annual Scientific Session supplement (J Nucl Cardiol 2007;14: S125), several lines are missing on page S125 in the Results section of Abstract 26.05. The corrected Results section is as follows:

Results: The mean age of the cohort was $61 \pm 12$. LVEF measured by SPECT was $63 \pm 12 \%$, LVEDV $(137 \pm 59 \mathrm{ml})$, and LVESV $(55 \pm 39 \mathrm{ml})$ : all correlated significantly with CMR $(58 \pm 11 \%, 141 \pm 37 \mathrm{ml}$, and $62 \pm 31 \mathrm{ml} ; \mathrm{r}=0.76,0.66$, and 0.85 , respectively; $\mathrm{p}$ all $<0.001$ ). Regional $\% \mathrm{TF}$ correlated weakly between SPECT and CMR $(r=0.22, p<0.001)$. In subgroup analysis, LGE was present in $41 \%$ of subjects. An abnormal \% TF was significantly related to the presence of myocardial scar $\left(\chi^{2}=19.8, p<0.001\right)$ and an upstream CAS $>70 \%\left(\chi^{2}=10.9, \mathrm{p}<0.001\right)$.

\section{CORRECTION}

In the Table of Contents of the September/October 2007 issue of Journal of Nuclear Cardiology (J Nucl Cardiol 2007;14:2A), and on the first page of the Editorial Point of View section (J Nucl Cardiol 2007;14:634-44), the location of Rory Hachamovitch, MD, MSc, was incorrectly listed as New York, NY. Rather, Dr. Hachamovitch is located in Los Angeles, Calif. The correct address for correspondence is 6380 Wilshire Blvd, Ste 1109, Los Angeles, CA 90048. The publisher of the Journal of Nuclear Cardiology regrets this error. 